American Journal of Environmental Sciences 4 (6): 638-648, 2008

ISSN $1553-345 \mathrm{X}$

(C) 2008 Science Publications

\title{
Environmental Characterisation of a Nuclear Site Saluggia (VC) (Italy)
}

\author{
Marina De Maio, Adriano Fiorucci \\ DITAG-Politecnico di Torino, C.so Duca Degli Abruzzi, 24, 10129 Torino, Italy
}

\begin{abstract}
This study, carried out in collaboration with SOGIN (Società Gestione Impianti Nucleari Nuclear Treatment Plant Management Company), is an integral part of environmental characterisation activity in the area where the EUREX treatment plant is situated, near Saluggia (North West Italy). With the aim of depicting the base conditions for the environment, which will then be used to develop decommissioning activities for the plant itself, a series of criteria have been defined in order to enable the identification of the present state of the environment, i.e. geologic, hydrogeologic and chemical structure, intrinsic and integrated vulnerability and land use. The study area is situated over an unconfined aquifer in a porous media of alluvial origin in the plain on the left bank of the Dora Baltea river. The whole area is strongly affected by human activities including industrial activities, extensive areas dedicated to agricultural use, quarries and numerous hamlets.
\end{abstract}

Key words: Environmental characterisation, intrinsic vulnerability, integrated vulnerability, nuclear site

\section{INTRODUCTION}

The aim of the study was to draw up as complete as possible a representation of the geologic, hydrogeological and vulnerability status of the groundwater resources associated with the site of the EUREX nuclear processing plant in Saluggia. This representation has enabled us to describe the present and where possible the past, vulnerability status of the resources and to outline the problems this may cause or has already caused, so as to create a technical policy tool for the overall decommissioning project.

\section{MATERIALS AND METHODS}

Guidelines for the environmental characterisation study of a nuclear site: We can summarise the procedure we adopted for the environmental characterisation of the nuclear site, which is to be remediated and restored, as follows:

- Selection, critical revision and then stratigraphic and hydrogeologic interpretation of the individual survey data for the subsurface and of the overall body of data

- Identification of the geometry of the hydrogeologic complexes forming the subsurface, in which the principal and characterising features of the hydrogeological structures forming them were ascertained
- Singling out the various existing aquifer systems and their hydrodynamic links (interflow) where present

- Delineating boundary conditions, when present and relations with surface water bodies and with irrigation practices

- Evaluation of the aquifers' vulnerability to contamination

Within the limits of the available data, the various aquifer bodies were identified with respect to: the coefficient of hydraulic conductivity and/or transmissivity obtained by analysis of aquifer test data and/or by processing available data for specific discharge, point by point, using QSEC code (Civita, 1997), operational discharge and average annual dewatering volumes base quality of groundwater, classified using the method designed and approved by the CNR-GNDCI (Consiglio Nazionale delle RicercheGruppo Nazionale per la Difesa dalle Catastrofi Idrogeologiche, National Research Council-National Group for Prevention from Hydro-Geological Disasters).

The data was collected as thoroughly and as completely as possible and was then collated and analysed to produce a series of results as follows:

- characteristics of the subsurface from both the geologic and hydrogeologic points of view

- hydrometric and hydrographical data, not only for

Corresponding Author: Marina De Maio, DITAG-Politecnico Di Torino, C.so Duca Degli Abruzzi, 24, 10129 Torino, Italy 
the natural water courses but also for the manmade canals

- time series of the piezometric levels

- relationships between inflows and outflows

- geochemical data

- $\quad$ soil type and structure

- hydrogeologic parameters of the aquifers

It was immediately obvious that the hydrogeologic characteristics of the zone would be important in identifying any critical situations that may be present, which was the purpose of the study. It was therefore of fundamental importance that we were able to find historic data such as the time series for the hydrogeologic data needed to evaluate the recharge/discharge processes of the various aquifers, in addition to existing time series and the readings made in the course of the study, with respect to hydraulic head and depth to water table data.

Suitable measurement points were found to be observation wells, sections of water courses, artificial canals and easily-reached quarry pits, where the real water level was measured. Equally useful were wells for irrigation, domestic, drinking water and industrial use, which were measured in the absence of pumping during the survey period so that the measurements of depth to water table would not be distorted by possible draft activities.

After verification in the field of the actual suitability of each recording point, their exact positions were determined using the GPS (hand-held TRIBLE Geo-Explorer 3 receiver). Differential corrections were applied: the position difference was calculated with respect to a second "base" receiver, simultaneously with acquisition of position and altitude, thus eliminating spatially correlated common errors.

In order to characterise the unconfined aquifer, as well as using piezometric data and the characteristics of the aquifers based on the information gathered, it was necessary to determine the hydrochemic characteristics of the water bodies.

Data for a total of 115 stratigraphic descriptions were used, of the following types:

- Five observation wells, which were shallow but useful in providing a detailed description of the parts closest to the surface of the youngest complexes

- Twenty three geologic columns with descriptions for depths varying from $10-50 \mathrm{~m}$, which, like the observation wells, provided a clear description of the encountered lithotypes
- Eighty-seven stratigraphic descriptions taken for wells of extremely variable depths

The material we collected, together with the results of our measurements enabled us to produce the following documents, each of which give a full description of the present situation and make it possible to draw up the monitoring plan:

- Map of hydrogeological complexes

- Iso - depth contour map of the unconfined aquifer

- Hydrogeologic profiles

- Flow field map for the unconfined aquifer

- Map showing intrinsic vulnerability to contamination of the unconfined aquifer

- Map of principal hazard points (CSC) and nonpoint (diffuse) contamination sources (DSC)

- $\quad$ Soil use map

Geomorphological and geological characterisation: The territory covered by the study occupies a small part of the Piedmont plain, straddling the administrative provinces of Turin and Vercelli, declining towards the south and bordered by the Ivrea moraine amphitheatre to the north and the Chivasso-Casale hill to the south (Fig. 1). This sector is crossed by the Po and Dora Baltea rivers, the latter flowing from the heights of the Ivrea moraine amphitheatre with a highly meandering course in an overall N-S direction, until it joins the Po. The Po, on the other hand flows approximately W-E through a stretch of plain with a wealth of oxbows and secondary branches of the river itself, as well as a number of small springs.

The eastern sector is the site of a series of dimple springs, while towards the $\mathrm{W}$ several small springs border the terrace along the river Dora Baltea.

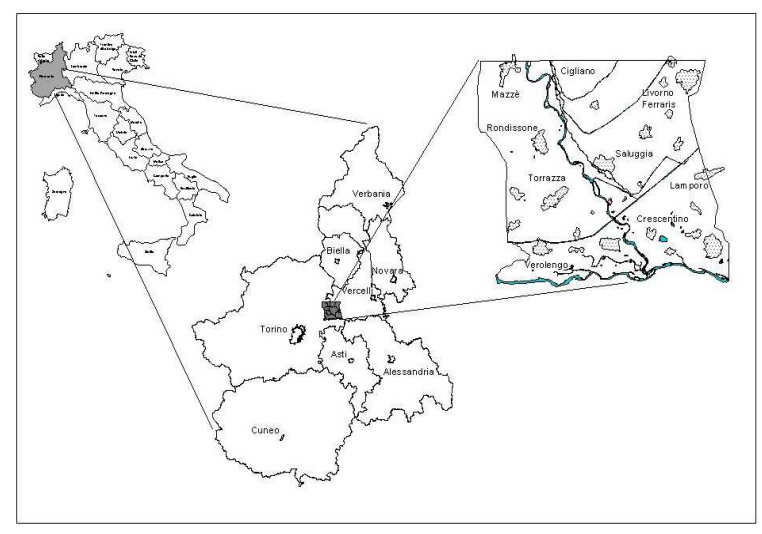

Fig. 1: Location of the study area 
Numerous canals cross the territory including the Cavour Canal, the Ivrea Naviglio, the Rotto Canal, the Depretis Canal and a large number of least and minor canals. There are also quarry pits in abundance, particularly in the south most area of the zone under study, as well as areas with working and disused quarries.

Over a large part of the territory, alluvial-type deposits are found on the surface and a minimal part has finer sediments of lacustrine origin, while deep down it is possible to identify sediments from transitional and marine environments.

On the basis of records taken in the field and the data contained in the numerous stratigraphic descriptions, the following complexes were identified, shown in Table 1 and Fig. 2.
Hydrogeologic structure: After defining the hydrogeological complexes and applying the collected data and measurements, it was possible to distinguish 3 aquifers:

- Perched aquifer

- Unconfined aquifer

- Deep aquifer

The deep aquifer was distinguished solely on the basis of bibliographical data, from which it was possible to deduce the presence of a multi-layer aquifer under pressure, contained in the coarser layers of the plio-pleistocene deposits.

Table 1: Description of identified hydrogeological complexes

\begin{tabular}{|c|c|c|c|c|}
\hline Hydrogeological complex & Description of complex & Thickness (m) & Permeability $(\mathrm{m} / \mathrm{s})$ & Notes \\
\hline Recent alluvial complex & $\begin{array}{l}\text { Sand and gravel of alluvial } \\
\text { origin with little or no change. } \\
\text { Rare argillaceous lenses. }\end{array}$ & Approx. $10 \mathrm{~m}$. & $\begin{array}{l}\text { Mostly of the order } \\
\text { of } 1 \mathrm{E}-03 \mathrm{~m} / \mathrm{s} \text {. }\end{array}$ & $\begin{array}{l}\text { Contains the unconfined } \\
\text { aquifer. Low depth to } \\
\text { water table values. }\end{array}$ \\
\hline Main alluvial complex & $\begin{array}{l}\text { Sand and gravel of alluvial and } \\
\text { alluvial-glacial origin, } \\
\text { alternating with layers of clay. }\end{array}$ & $\begin{array}{l}\text { From } 10 \mathrm{~m} \text { to } \\
\text { over } 70 \mathrm{~m} .\end{array}$ & $\begin{array}{l}\text { Varying between values } \\
\text { of the order of } 1 \mathrm{E}-03 \\
\text { and } 1 \mathrm{E}-05 \mathrm{~m} / \mathrm{s} \text {. }\end{array}$ & $\begin{array}{l}\text { Contains the unconfined } \\
\text { aquifer and the perched } \\
\text { aquifer. Extremely variable } \\
\text { depths to water table. }\end{array}$ \\
\hline Sandy-Clay complex & Sandy clays of lacustrine origin. & From 5 to $10 \mathrm{~m}$. & Several metres & $\begin{array}{l}\text { Extremely limited. Not the site } \\
\text { of an aquifer. Constitutes the } \\
\text { base of the perched aquifer. }\end{array}$ \\
\hline $\begin{array}{l}\text { Alternating layer } \\
\text { complex }\end{array}$ & $\begin{array}{l}\text { Alternating gravel, } \\
\text { sand and silt. }\end{array}$ & $\begin{array}{l}\text { From } 10 \text { to } 150 \mathrm{~m} . \\
\text { Inexistent at some points. }\end{array}$ & $\begin{array}{l}\text { In the coarser layers of } \\
\text { the order of } 1 \mathrm{E}-04\end{array}$ & $\begin{array}{l}\text { Contains the multilayer } \\
\text { aquifer. }\end{array}$ \\
\hline Sandy-slimly complex & $\begin{array}{l}\text { Silt and sand of marine } \\
\text { and coastal origin. }\end{array}$ & Unknown. & Very low (estimated) & $\begin{array}{l}\text { Lower portion of the sequence } \\
\text { identified. }\end{array}$ \\
\hline
\end{tabular}

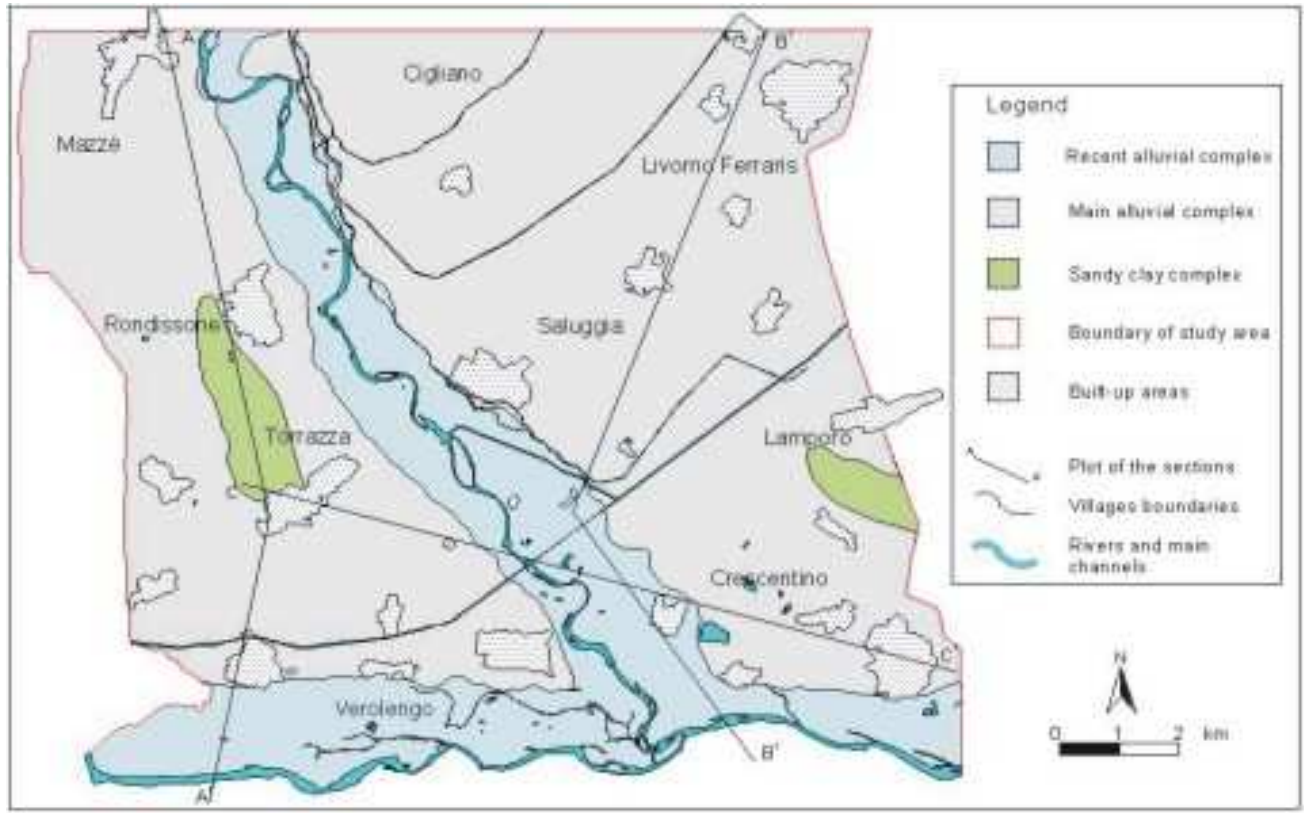

Fig. 2: Map of hydrogeological complexes 


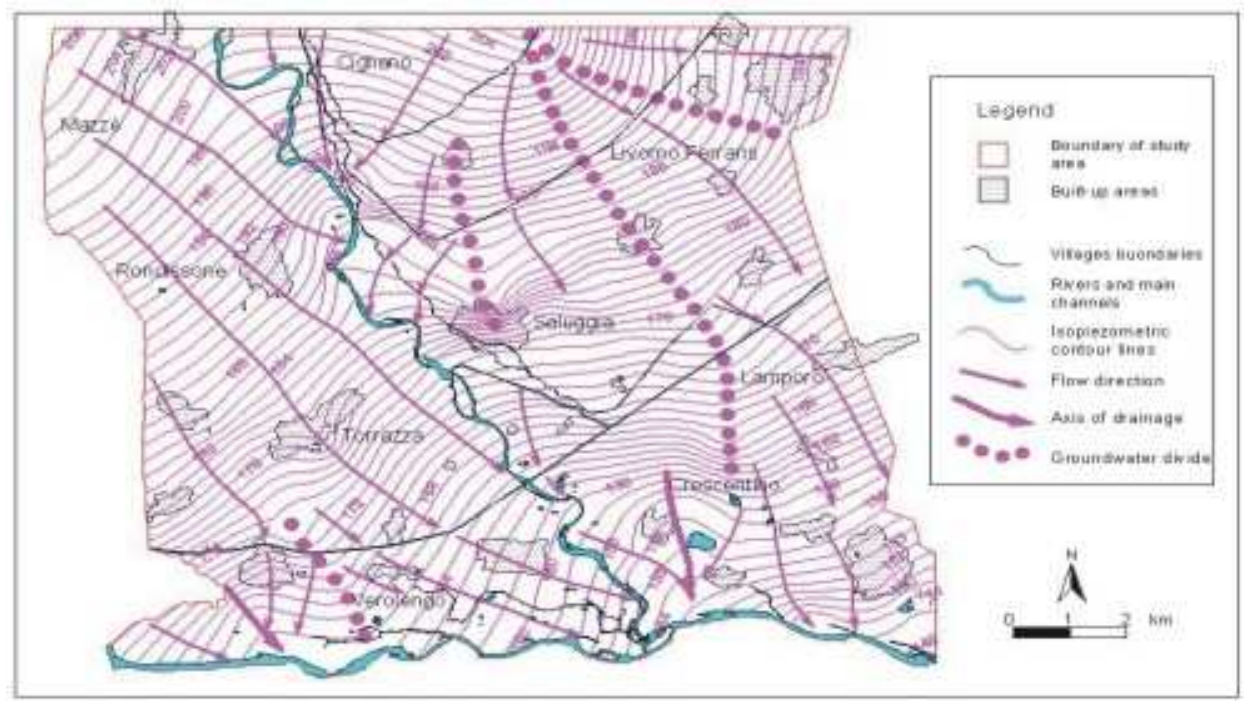

Fig. 3: Flow field map of the unconfined aquifer

The surficial aquifer is present only in the north-eastern sector of the zone under examination (on the right bank of the River Dora Baltea) and its lower boundary is marked by the sandy-argillaceous complex. This aquifer has somewhat limited depths to water table and a series of springs (E-wards) that limit its extension downwards.

The unconfined aquifer has been subjected to a more detailed study and description in that its intrinsic vulnerability has been determined. It occupies the whole plain under examination and is contained within the main alluvial and recent alluvial complexes. The joint thickness of the two complexes varies from approx. $10 \mathrm{~m}$ near the Po to approx $80 \mathrm{~m}$ towards NE.

Unconfined aquifer: The flow field of the unconfined aquifer (Fig. 3) showed some degree of regularity in the isopiezometric contour lines. Their equidistance is practically constant, with small differences near the Po and Dora Baltea rivers and corresponding with the known groundwater divides. The piezometric gradient is therefore quite regular, with the most frequent values at around between $0.2 \%$ and $0.3 \%$, excluding the areas near the groundwater divides and drainage lines.

In general, it is possible to identify drainage action on the part of both the Dora Baltea and the Po, which constitutes the local base level. While the Dora shows more marked drainage action in its central sector, this effect is less evident along the rest of its course. To the $\mathrm{N}$, the less pronounced drainage effect may be due to wide loops in the river itself, which necessarily widens the curvature of the isopiezometric lines. To the $\mathrm{S}$, on the other hand, the aquifer begins to be affected by the drainage effect of the Po, so that the isopiezometric lines are positioned practically perpendicular to the course of the Dora, denoting a condition of equilibrium between the Dora and the aquifer, with at most slight concavity in the downstream direction.

The flow lines tend to be directed SE-wards, although local distortions $\mathrm{S}$-wards or E-wards have been duly identified and noted. It is only in the southwestern sector that it is possible to observe strongly divergent flow lines due to a mobile groundwater divide of limited extent.

Depths to water table vary from sector to sector: in the north-western and central-western sectors, excluding the perched aquifer, depths to water table decrease progressively as one moves S-wards, reaching values of a few metres near the Po. Also along the Dora (on both the right and left banks) depths to water are limited to 1-2 m. Lastly, in the most easterly sector of the area of interest a series of dimple springs denotes the presence of scant or nil depths to water table (0-3 $\mathrm{m})$.

The Rivers Po and Dora Baltea have a drainage effect with respect to the unconfined aquifer, if the southern sector is excluded where the Dora is in equilibrium with the aquifer, but the possibility of their feeding the aquifer when in peak flow cannot be excluded.

Monitoring the piezometric levels reveals an annual cycle that is considerably disturbed by particularly intense rain (Fig. 4). The trend shows a rather slow increase (little over $2 \mathrm{~m}$ ) over a period of 45 months, but with quite a quick response to intense 


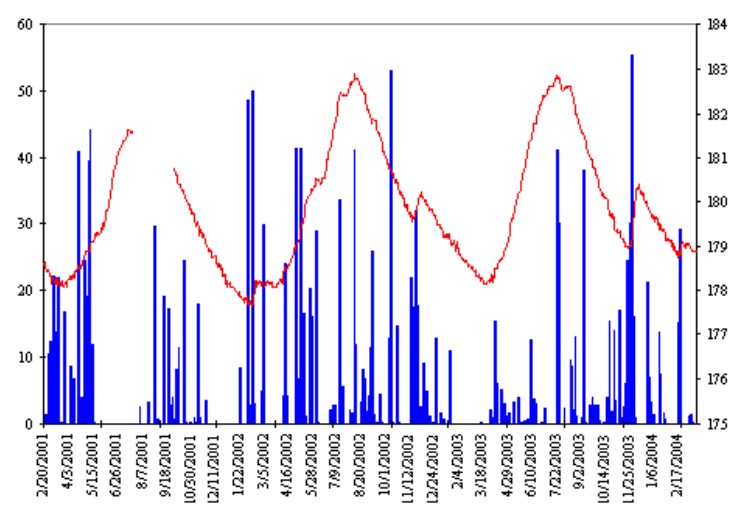

Fig. 4: Relations between the piezometric surface and precipitation

rain: it is obvious that the aquifer is fed in relation to the rainfall. It is possible that the aquifer is fed by some of the canals or part of them but this has not been proved. Only some sectors show strong exploitation of the unconfined aquifer by wells for industrial and drinking water use, as occurs at the confluence of the Dora Baltea and the Po, on the left bank of the Dora.

During extreme precipitation events, some parts of the area under study are subject to flooding by exudation and/or surfacing of the piezometric surface of the subjacent aquifer. These parts were identified on the left bank of the Po and at the confluence of the Dora with the Po.

\section{RESULTS AND DISCUSSION}

Intrinsic vulnerability of the unconfined aquifer: Using a global interpretation of the data for soil and subsurface (description of geologic and hydrogeological structure) and of measurements of depth to water table, infiltration, properties of the unsaturated portion of the aquifer, type of cover, properties of the saturated portion of the aquifer, calculations of hydraulic conductivity and acclivity of the topographical surface, it was possible obtain the intrinsic vulnerability of the unconfined aquifer, using the SINTACS R5 method ${ }^{[1]}$.

Intrinsic vulnerability (Fig. 5) ranges from extremely high to high over the whole area. The factors contributing to these values are reduced depth to water table values, high points awarded to infiltration and unsaturated parameters, the almost total lack of soil, the relatively flat topographical surface. It is above all the depth to water table factor that causes the absolute vulnerability level to decrease taking it to high or very high, although the latter level is only for small portions of the area under examination.

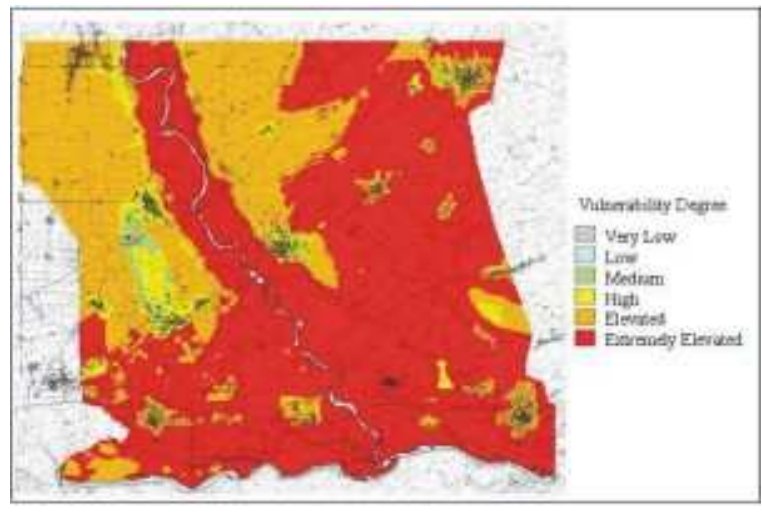

Fig. 5: Map of intrinsic vulnerability

Where the soil is deeper and depth to water table is quite high, there is medium vulnerability. The area examined is in actual fact characterised by mainly flat morphology. The subsurface is formed mainly of coarse sediment with medium-high permeability, there is practically no soil so that the areas of medium vulnerability are decidedly limited.

Impact is generally high due to the presence of vast cultivated areas (mainly maize) and numerous centres of population (though small in size). The areas of normal impact, on the other hand, are limited to zones adjacent to water courses and small, uncultivated sectors or where a variety of plants are cultivated.

The EUREX plant is situated right by the River Dora Baltea and hence where there is coarse sediment (gravel and sand) that has undergone hardly any or no change, with medium-high permeability, where there is no soil and the unconfined aquifer has low depth to water table values. It is therefore in an area with extremely high intrinsic vulnerability.

Integrated vulnerability and soil use: Once the intrinsic vulnerability of the zone has been determined, it is important to identify the presence of hazard points (CSC), of diffuse hazard sources (DSC), of objects at risk (SAR) and of pollution transmitters and attenuators in order to complete the description of the current environmental status in the area of interest.

Industry and small artisan-type manufacturing areas are mostly positioned near the centres of population. They are all connected to the sewage system or have their own waste water treatment system with the exception of a sheep product factory. The centres causing the highest pressures are the heavy industries present on the territory, such as a metallurgy plant, a copper-processing company, a number of furnaces and a plastic materials factory. 
In the area under study there are three natural gas pipelines supplying the centres of population and two oil pipelines which, despite their limited presence in the area, could have a considerable impact given the type of material they carry.

Sewage networks, settlement tanks for suspended solids and biological treatment tanks are also prone to leakages. The main drains of the sewage network have therefore been indicated and also the villages lacking this service. There are also eleven sewage treatment plants situated near the centres of population.

The pollution potential produced by animal farming depends on defecation composition including, first and foremost, nitrates carried into the subsurface. The area contains all types of animal farming, mostly in farmsteads situated away from the centres of population; the majority carry out cattle breeding (63\%), followed by poultry (17\%) and pigs (14\%) and lastly sheep farming $(6 \%)$.

There are also two sites of toxic liquid dumps (already remediated and restored), one remediated site in which a container of alumina is still present and three deposits of chemicals and other materials for agricultural use.

The principal objects subject to pollution have been identified: wells, springs and aqueduct networks (collection works, supply pipes, tanks, protected areas etc.). Every municipality has an aqueduct feeding both the most densely populated zones and isolated farmsteads. There are collection wells for drinking water near the main centres of population. There is also a well field near the Cascina Giarrea farm in Saluggia municipality, which supplies many bordering municipalities and the Monferrato Aqueduct. The most important industries have one or more wells, while most of the farmsteads are connected to the aqueduct and use the water for their animal farming as well. There are few wells for agricultural use because mainly flood irrigation is practiced, from the numerous canals and channels present in the area.

In all, the urban areas cover about $6 \%$ of the area under consideration.

Determining the positions of the potentially polluting sites clarified the relationship between the intrinsic properties of the aquifer and possible polluting events. Most of the hazard points that were identified, whether point or diffuse sources, are situated inside the areas of extremely high vulnerability, as are most of the quarries, whether working or filled in.

In a situation where human activity has an appreciable impact on groundwater resources (confirmed by results of chemical analysis), due to both farming practice and point sources of pollution from industrial activity and uncontrolled waste disposal, further possible pollution sources can only worsen today's already precarious situation.

In addition to the data points for hazard points (CSC's and DSC's) and for the objects at risk (SAR's), fundamental information regarding environmental characterization of this area comes from soil use., Information was initially taken from official cartography and was then fully revised and corrected by work in the field, leading to the following conclusions.

A large part of the area of interest, occupying a total of $168 \mathrm{~km}^{2}$, is covered by various types of cultivation (approx. $110 \mathrm{~km}^{2}$ ). The largest area by far is given over to maize growing (just below $100 \mathrm{~km}^{2}$ ), while wheat fields occupy very small portions. In the most easterly part of the area under examination there is a segment of rice fields (almost $10 \mathrm{~km}^{2}$ ).

The centres of population occupy small areas (the largest covers about $1.7 \mathrm{~km}^{2}$ ) within the extensive area used for crop-growing.

Although they are of extremely variable size and the majority is very small, quarries occupy a significant portion of the territory being analysed (over one square kilometre). Some are disused, while others are working so that their geometry has changed noticeably in the course of several months. In order to present consistent data, properties for the summer-autumn of 2004 have been presented, but recent inspections have revealed considerable changes.

A total of 47 quarries were surveyed, of which 14 are working, 22 are abandoned and 11 are filled in. The working and abandoned quarries cover about $2 \%$ of the area under study. Quarrying activities comprised sand and gravel extraction and a number of clay extraction sites. The largest quarries are those for the construction sites building the Turin-Milan high-speed railway.

In the territory being studied there are three authorised category 2, type A landfills and two of category 2 , type B.

The rest of the area corresponds to zones characterised mainly as ordinary river beds or poplar plantations, while bushy areas, permanent grassland and mixed non-coniferous woodland occupy a small portion.

Geochemistry: The hydrogeochemic study of the unconfined aquifer was carried out with a sampling programme covering 19 sampling points, the location of which is shown in Fig. 6.

The sampling points were distributed as follows:

- Sector to the right of the Dora Baltea (SAL01, SAL03, SAL04, SAL06, SAL07, SAL13, SAL15 and SAL19) 
- Sector to the left of the Dora Baltea (SAL10, SAL11, SAL14, SAL16, SAL17 and SAL18)

- Dora Baltea torrent (SAL02, SAL05 and SAL09)

- River Po (SAL08 and SAL12)

The results of analysis are shown in Table 2 .

Considering the values of specific electrical conductivity at $20^{\circ} \mathrm{C}(\mathrm{EC})$, all the water samples can be classed as medium-mineral.

For the hydrogeochemic facies study, the Schoeller Diagram $^{[2]}$ was used, showing values by individual sector.

In the Sector to the right of the Dora Baltea (Fig. 7) the dominant facies is bicarbonate-calcic-magnesic, although the presence of bicarbonate-calcic and bicarbonate magnesic-calcic facies were noted.

Samples SAL04 and SAL07 had higher chloride and alkaline values than the samples taken elsewhere.

The $\mathrm{Mg}^{2+} / \mathrm{Ca}^{2+}$ ratio should be noted, showing noticeably different values, swinging between 0.307 (SAL07) and 1.375 (SAL19).

The facies analysis is, however, disturbed by the non-negligible presence of nitrates that may alter other parameters.

The situation in the Sector to the right of the Dora Baltea (Fig. 7) gives more uniform results compared to the above sector. Nitrate interference is repeated here, maintaining values that demonstrate serious disturbance. The facies is bicarbonate-calcic for all analysed samples.

The $\mathrm{Mg}^{2+} / \mathrm{Ca}^{2+}$ ratio falls within the limited range of 0.134 (SAL10) to 0.419 (SAL11).

The rivers (Po and Dora Baltea) have a main bicarbonate-calcic facies and a sulphate-magnesic subfacies (Fig. 7) the only difference being due to the presence of chlorides and alkalis, which are higher in the case of the River Po than those for the Dora Baltea.

Comparison of average values for the two sectors and rivers clearly shows that the sector to the right of the Dora Baltea has a bicarbonate-calcic-magnesic facies, the sector to the left of the Dora Baltea is in a bicarbonate- calcic facies while the rivers have a complex bicarbonate-calcic facies with a sulphatemagnesic sub-facies.

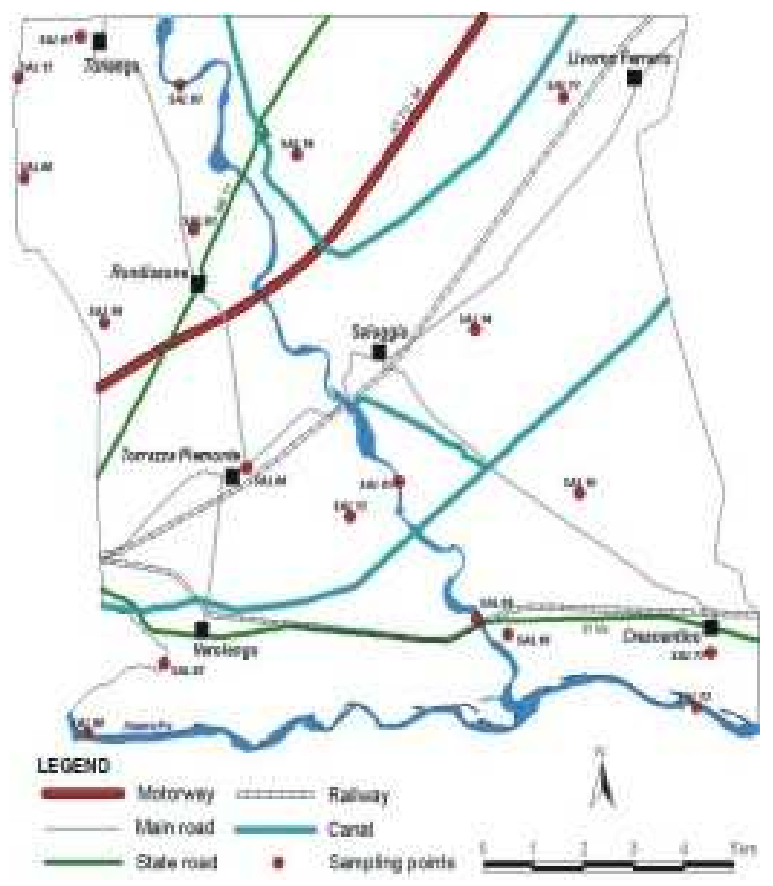

Fig. 6: Location of sampling sites

Table 2: Chemical analysis of samples taken

\begin{tabular}{|c|c|c|c|c|c|c|c|c|c|c|c|c|}
\hline Sample & $\mathrm{pH}$ & $\begin{array}{l}\mathrm{TH} \\
{\left[{ }^{\circ} \mathrm{f}\right]}\end{array}$ & $\begin{array}{l}\mathrm{EC} \\
{\left[\mu \mathrm{S} \mathrm{cm}^{-1}\right]}\end{array}$ & $\begin{array}{l}\mathrm{Ca}^{2+} \\
{\left[\mathrm{mg}^{-1}\right]}\end{array}$ & $\begin{array}{l}\mathrm{Mg}^{2+} \\
{\left[\mathrm{mg} \mathrm{L}^{-1}\right]}\end{array}$ & $\begin{array}{l}\mathrm{Na}^{+} \\
{\left[\mathrm{mg} \mathrm{L}^{-1}\right]}\end{array}$ & $\begin{array}{l}\mathrm{K}^{+} \\
{\left[\mathrm{mg} \mathrm{L}^{-1}\right]}\end{array}$ & $\begin{array}{l}\mathrm{Cl}^{-} \\
{\left[\mathrm{mg} \mathrm{L}^{-1}\right]}\end{array}$ & $\begin{array}{l}\mathrm{SO}_{4}^{2-} \\
{\left[\mathrm{mg} \mathrm{L}^{-1}\right]}\end{array}$ & $\begin{array}{l}\mathrm{HCO}_{3}^{-} \\
{\left[\mathrm{mg} \mathrm{L}^{-1}\right]}\end{array}$ & $\begin{array}{l}\mathrm{NO}_{3}^{-} \\
{\left[\mathrm{mg} \mathrm{L}^{-1}\right]}\end{array}$ & $\begin{array}{l}\mathrm{SiO}_{2} \\
{\left[\mathrm{mg} \mathrm{L}^{-1}\right]}\end{array}$ \\
\hline SAL01 & 7.91 & 15 & 278 & 41.28 & 11.43 & 2.53 & 0.52 & 3.05 & 8.93 & 151.32 & 19.31 & 19.61 \\
\hline SAL02 & 7.80 & 16 & 309 & 48.90 & 9.72 & 5.00 & 1.29 & 5.65 & 53.68 & 128.80 & 3.88 & 6.51 \\
\hline SAL03 & 6.81 & 10 & 210 & 28.86 & 7.54 & 2.88 & 2.93 & 3.84 & 14.55 & 74.81 & 25.27 & 14.40 \\
\hline SAL04 & 6.97 & 11 & 254 & 25.25 & 10.21 & 11.82 & 3.28 & 13.92 & 17.10 & 85.24 & 20.07 & 9.27 \\
\hline SAL05 & 7.97 & 16 & 290 & 43.69 & 11.18 & 4.30 & 1.33 & 6.84 & 38.21 & 122.70 & 9.17 & 11.65 \\
\hline SAL06 & 6.89 & 10 & 201 & 19.64 & 11.91 & 2.70 & 0.94 & 4.79 & 9.53 & 74.44 & 28.76 & 19.44 \\
\hline SAL07 & 7.88 & 23 & 429 & 71.74 & 13.37 & 9.41 & 1.17 & 14.06 & 22.30 & 252.06 & 17.61 & 19.90 \\
\hline SAL08 & 8.08 & 20 & 405 & 54.51 & 15.56 & 10.48 & 1.51 & 13.71 & 59.60 & 148.33 & 12.22 & 9.46 \\
\hline SAL09 & 8.16 & 15 & 281 & 47.69 & 6.56 & 3.80 & 1.01 & 4.74 & 46.58 & 107.63 & 4.66 & 6.62 \\
\hline SAL10 & 7.57 & 25 & 500 & 89.78 & 7.29 & 6.58 & 1.68 & 11.19 & 54.72 & 209.83 & 22.95 & 14.20 \\
\hline SAL11 & 7.32 & 19 & 355 & 50.51 & 13.86 & 3.92 & 1.77 & 7.19 & 31.78 & 157.79 & 28.87 & 15.62 \\
\hline SAL12 & 7.87 & 19 & 406 & 59.32 & 10.70 & 9.85 & 1.59 & 15.40 & 60.49 & 143.75 & 14.06 & 9.46 \\
\hline SAL13 & 7.22 & 18 & 332 & 46.09 & 15.07 & 4.10 & 1.05 & 9.28 & 26.96 & 146.44 & 27.08 & 17.53 \\
\hline SAL14 & 6.89 & 15 & 301 & 44.89 & 9.48 & 3.83 & 1.32 & 7.15 & 28.21 & 99.46 & 38.13 & 14.45 \\
\hline SAL15 & 6.90 & 12 & 213 & 25.25 & 13.12 & 2.69 & 0.49 & 4.64 & 9.00 & 91.28 & 29.96 & 23.83 \\
\hline SAL16 & 7.36 & 18 & 346 & 52.50 & 12.40 & 2.92 & 0.86 & 6.66 & 34.87 & 158.76 & 22.68 & 11.44 \\
\hline SAL17 & 7.31 & 12 & 249 & 39.28 & 5.35 & 3.93 & 2.33 & 5.91 & 28.25 & 87.50 & 25.13 & 11.92 \\
\hline SAL18 & 6.75 & 13 & 253 & 38.08 & 7.29 & 5.10 & 3.42 & 7.53 & 28.59 & 97.01 & 15.60 & 8.27 \\
\hline SAL19 & 6.85 & 10 & 194 & 16.03 & 13.37 & 2.79 & 0.79 & 4.57 & 9.66 & 59.19 & 37.83 & 16.48 \\
\hline
\end{tabular}




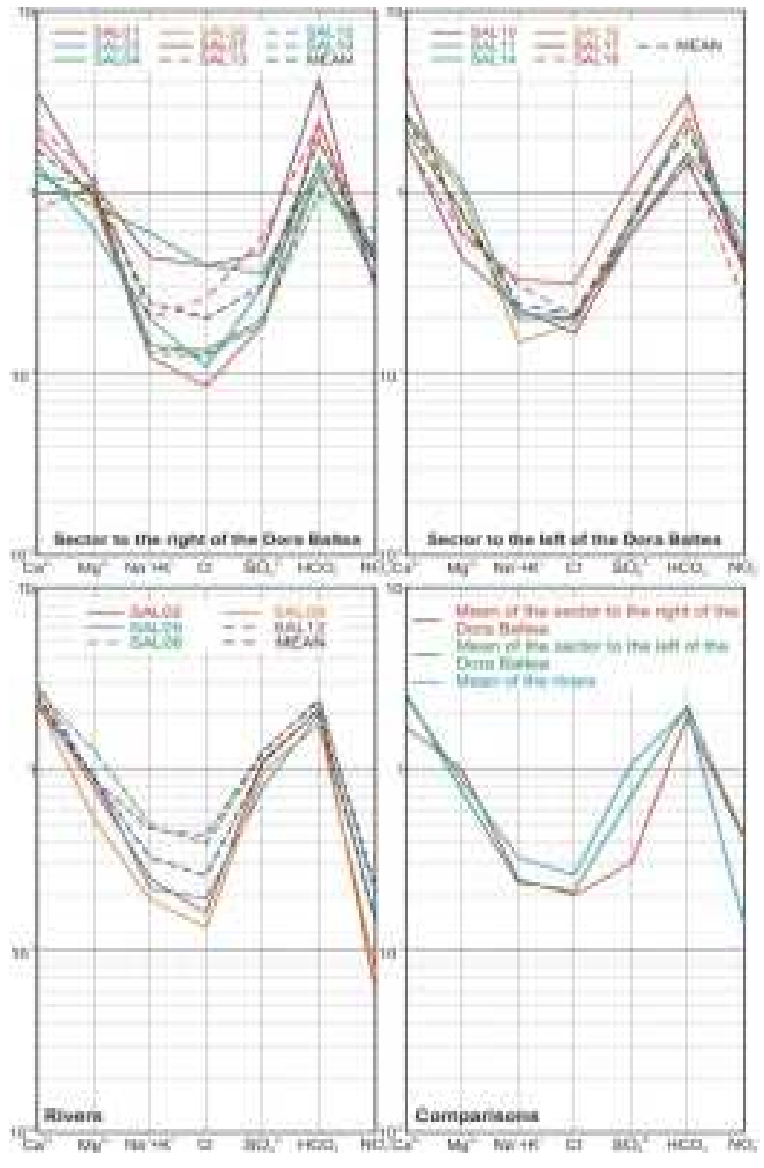

Fig. 7: Schoeller diagram (values expressed in meq $\mathrm{L}^{-1}$ )

The information obtained from the hydrogeochemic data agrees with the results of the flow field analysis that identified the two water courses as drainage areas for the aquifer, therefore the fact that they have a particular facies is entirely plausible because they are the consequence of a hydrogeological catchments basin that is lithologically different from the one under examination.

Quality of groundwater resources: Evaluation of the quality of a water resource is a basic step in order to decide how to utilize the resource itself and to develop the correct policy for the territory that will lead to strategic decisions aimed at balancing social-economic development against environmental protection requirements.

Quality for use as drinking water: To evaluate the quality of the groundwater resource for use as drinking water the CNR-IRSA ${ }^{[3]}$ method was applied, in compliance with Italian law DPR 236/88.
Table 3: Values of parameters describing base quality for use drinking water

\begin{tabular}{lccc}
\hline Camp. & $\mathrm{NH}_{4}{ }^{+}\left[\mathrm{mg} \mathrm{L}^{-1}\right]$ & $\mathrm{Fe}\left[\mathrm{mg} \mathrm{L}^{-1}\right]$ & $\mathrm{Mn}\left[\mathrm{mg} \mathrm{L}^{-1}\right]$ \\
\hline SAL01 & $<0.010$ & $<0.010$ & $<0.010$ \\
SAL02 & 0.215 & 0.320 & $<0.010$ \\
SAL03 & $<0.010$ & $<0.010$ & $<0.010$ \\
SAL04 & $<0.010$ & 0.121 & $<0.010$ \\
SAL05 & $<0.010$ & 0.256 & $<0.010$ \\
SAL06 & $<0.010$ & 0.112 & 0.012 \\
SAL07 & $<0.010$ & $<0.010$ & $<0.010$ \\
SAL08 & 0.383 & 0.091 & 0.014 \\
SAL09 & $<0.010$ & 0.310 & $<0.010$ \\
SAL10 & $<0.010$ & $<0.010$ & $<0.010$ \\
SAL11 & $<0.010$ & $<0.010$ & $<0.010$ \\
SAL12 & 0.360 & $<0.010$ & $<0.010$ \\
SAL13 & $<0.010$ & $<0.010$ & $<0.010$ \\
SAL14 & $<0.010$ & 0.491 & $<0.010$ \\
SAL15 & $<0.010$ & 0.114 & $<0.010$ \\
SAL16 & $<0.010$ & 0.052 & $<0.010$ \\
SAL17 & $<0.010$ & $<0.010$ & 0.037 \\
SAL18 & $<0.010$ & 0.840 & 0.067 \\
SAL19 & $<0.010$ & 0.184 & $<0.010$ \\
\hline
\end{tabular}

This method, which is widely used in many parts of Italy, envisages cartographic data-processing to produce a quality map for the territory in order to provide better support for planning decisions.

The parameters considered are: total hardness, specific electrical conductivity at $20^{\circ} \mathrm{C}$, chlorides, sulphates, nitrates, ammonium ion, iron and manganese.

The values of the above parameters that were obtained during the sampling programme for the 19 points under consideration are given in Table 3 with the data for the rivers (not used in producing the cartography) shown only for comparison purposes.

Analysis of the map

of base quality of the unconfined aquifer Fig. 8 shows that for about one third of the area being surveyed (31\%), the aquifer is of excellent quality; this sector is mainly represented by the right bank of the Dora Baltea Stream. The remainder of the analysed area falls in the acceptable quality (39\%) and poor quality (30\%) classes.

This downgrading of quality is fundamentally due to the iron and manganese content, although we should also note that the aquifer under examination is characterised by widespread presence of nitrates in concentrations that are significantly higher than the $5 \mathrm{mg} \mathrm{L}{ }^{-1}$ that represent the "natural" threshold below which the impact of human activity may be considered irrelevant. The groundwater resource being examined has therefore been harmed and given that the area is one of extremely high vulnerability, it follows that the harm already done is susceptible to aggravation. Having said this, it should be specified that the classification as excellent applied to class B1A2 should not be 


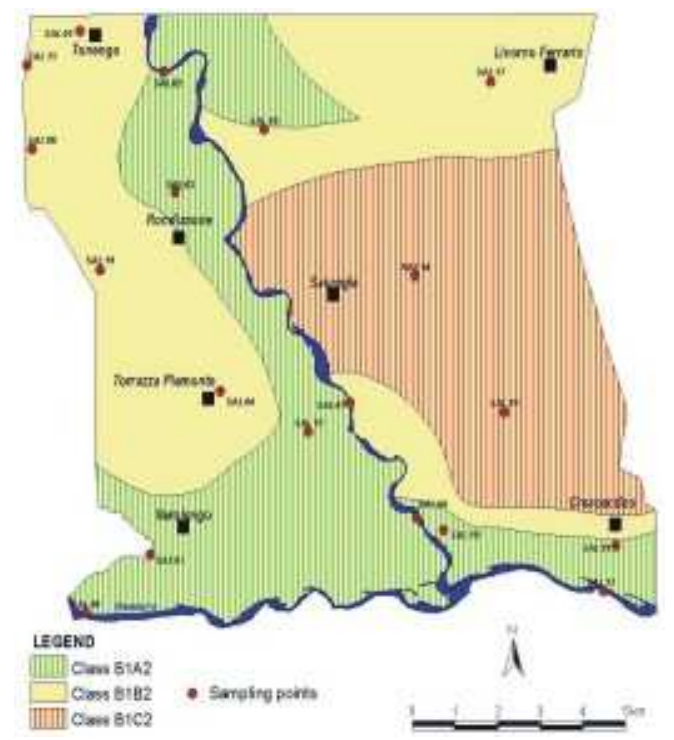

Fig. 8: Map showing base quality for use as drinking water

interpreted as a resource of high value, but as a resource that is suitable for use as drinking water with low treatment costs.

We should also point out that the base quality map of the unconfined aquifer represents the quality status of the water resource at the time of sampling and is therefore subject to change over time especially if there has been significant human activity affecting the system. Therefore, to be as useful as possible these graphical results must be considered in conjunction with the evaluation of vulnerability in order to provide important information as regards possible future scenarios.

Quality for agricultural use: The quality of the groundwater resource for agricultural use (irrigation in particular) has been evaluated according to a method formulated by ${ }^{[3]}$. This method is similar to the one used for drinking water but obviously also considers other parameters.

For this process the Diagrams for evaluation of water quality for irrigation were used ${ }^{[3]}$.

Parameters considered were specific electrical conductivity at $25^{\circ} \mathrm{C}$, chloride and sulphate concentrations, TDS (Total Dissolved Solids) and SAR (Sodium Adsorption Ratio) and RSC (Residual Sodium Carbonate) indicators.

SAR is used to evaluate the effects attributable to the presence of sodium in irrigation water. SAR is defined as:
Table 4: Parameter values for evaluating quality for use in irrigation.

\begin{tabular}{lllll}
\hline Camp. & SAR & \multicolumn{2}{c}{ TDS $\left[\mathrm{mg} \mathrm{L}^{-1}\right]$ CE $25^{\circ} \mathrm{C}_{\left[\mu \mathrm{cm}^{-1}\right]}$ RSC $\left[\mathrm{meq} \mathrm{L}{ }^{-1}\right]$} \\
\hline SAL01 & 0.090 & 257.98 & 309 & -0.520 \\
SAL02 & 0.170 & 263.44 & 343 & -1.130 \\
SAL03 & 0.120 & 175.08 & 233 & -0.830 \\
SAL04 & 0.500 & 196.16 & 282 & -0.700 \\
SAL05 & 0.150 & 249.08 & 322 & -1.090 \\
SAL06 & 0.120 & 172.16 & 223 & -0.740 \\
SAL07 & 0.270 & 421.62 & 477 & -0.550 \\
SAL08 & 0.320 & 325.39 & 450 & -1.570 \\
SAL09 & 0.140 & 229.31 & 312 & -1.160 \\
SAL10 & 0.180 & 418.22 & 555 & -1.640 \\
SAL11 & 0.120 & 315.30 & 394 & -1.270 \\
SAL12 & 0.310 & 324.63 & 451 & -1.480 \\
SAL13 & 0.130 & 293.60 & 369 & -1.140 \\
SAL14 & 0.140 & 246.92 & 334 & -1.390 \\
SAL15 & 0.110 & 200.09 & 237 & -0.840 \\
SAL16 & 0.090 & 303.11 & 384 & -1.040 \\
SAL17 & 0.160 & 209.60 & 277 & -0.970 \\
SAL18 & 0.200 & 210.91 & 281 & -0.910 \\
SAL19 & 0.120 & 160.71 & 216 & -0.930 \\
\hline
\end{tabular}

$$
\mathrm{SAR}=\sqrt{\frac{\mathrm{Ca}^{2+}+\mathrm{Mg}^{2+}}{2}}
$$

where, the concentrations of the elements are expressed as milliequivalents/litre.

RSC is determined using the following formula:

$$
\mathrm{RSC}=\left(\mathrm{CO}_{3}^{2-}+\mathrm{HCO}_{3}^{-}\right)-\left(\mathrm{Ca}^{2+}+\mathrm{Mg}^{2+}\right)
$$

with the concentrations of the elements also expressed in milliequivalents/litre.

When this parameter takes positive values this means there is an excess of the hydrogen carbonate ion with respect to calcium and magnesium ions and it will be bound to other alkaline ions-sodium and potassium in particular; vice versa, negative values for RSC are obtained when there is an excess of calcium and magnesium cations with respect to the hydrogen carbonate ion, in which case the cations will be mainly bound to sulphates and/or chlorides.

The parameter TDS refers to the sum of the analytical concentrations of all the ions and of silica present in the water.

The value of the parameters used to evaluate quality for irrigation use are shown in Table 4, with the exception of those already given in Table 3 (sulphates and chlorides).

In the Diagrams for evaluating quality for irrigation use $^{[3]}$ (for further details) shown in Figs. 9 and 10, it should be noted that for both sectors of the unconfined aquifer under examination, $1^{\text {st }}$ Class Quality is obtained. In other words, the water resource that has been analysed is suitable for any type of soil. 


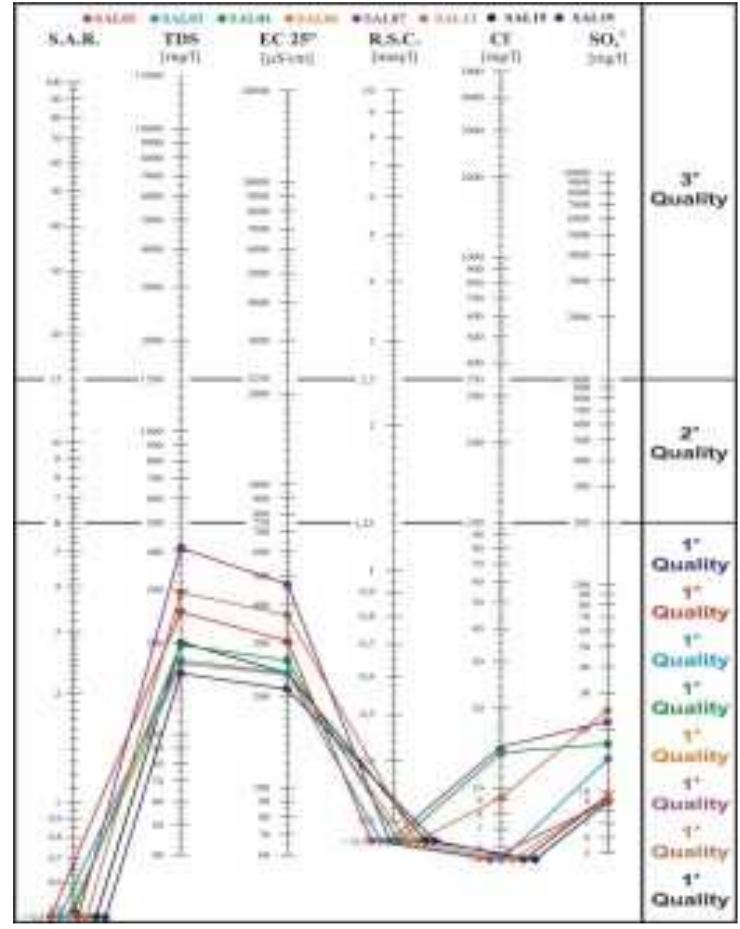

Fig. 9: Quality diagram for agricultural use (Sector to the right of the Dora Baltea)

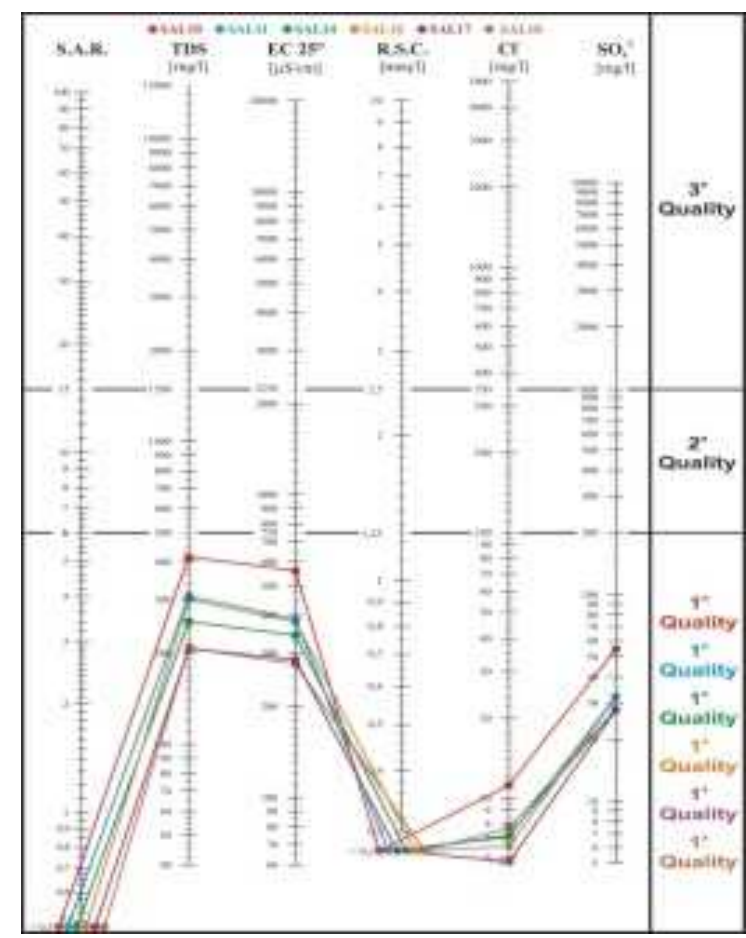

Fig. 10: Quality diagram for agricultural use (Sector to the left of the Dora Baltea)
Table 5: Metal concentrations in the samples taken (values in $\mu \mathrm{g} \mathrm{L}^{-1}$ )

\begin{tabular}{llllllll}
\hline Sample & $\mathrm{Al}$ & $\mathrm{Cd}$ & $\mathrm{Co}$ & $\mathrm{Cu}$ & $\mathrm{Ni}$ & $\mathrm{Pb}$ & $\mathrm{Zn}$ \\
\hline SAL01 & 10 & $<0.1$ & $<0.1$ & 1.1 & 0.7 & 0.6 & 4 \\
SAL02 & 19 & 0.2 & $<0.1$ & 2.5 & 5.7 & 0.9 & 3 \\
SAL03 & 10 & $<0.1$ & $<0.1$ & $<1.0$ & 75.9 & $<0.1$ & 1 \\
SAL04 & $<10$ & $<0.1$ & 1.1 & 6.5 & 101.6 & 0.9 & 76 \\
SAL05 & 15 & $<0.1$ & $<0.1$ & 1.5 & 4.2 & 1.0 & 3 \\
SAL06 & $<10$ & $<0.1$ & $<0.1$ & $<1.0$ & 336.4 & $<0.1$ & 14 \\
SAL07 & $<10$ & $<0.1$ & $<0.1$ & 9.1 & 9.9 & 13.6 & 377 \\
SAL08 & 11 & $<0.1$ & $<0.1$ & 4.3 & 6.1 & $<0.1$ & $<1$ \\
SAL09 & 14 & 0.1 & 0.1 & 2.0 & 5.5 & 0.9 & 3 \\
SAL10 & $<10$ & $<0.1$ & 1.3 & 7.4 & 2.7 & 1.3 & 16 \\
SAL11 & $<10$ & $<0.1$ & $<0.1$ & 6.2 & 4.0 & 1.6 & 79 \\
SAL12 & 10 & $<0.1$ & $<0.1$ & 2.8 & 6.5 & 3.7 & 13 \\
SAL13 & 10 & 0.1 & $<0.1$ & 3.6 & 20.8 & 1.6 & 37 \\
SAL14 & 10 & $<0.1$ & $<0.1$ & 2.0 & 23.1 & $<0.1$ & 6 \\
SAL15 & $<10$ & 0.2 & $<0.1$ & 9.6 & 11.1 & 0.8 & 165 \\
SAL16 & $<10$ & 3.9 & $<0.1$ & $<1.0$ & 1.6 & 22.0 & 6667 \\
SAL17 & 12 & 0.7 & 5.2 & $<1.0$ & 41.5 & 202.0 & 1902 \\
SAL18 & $<10$ & 1.0 & $<0.1$ & 25.0 & 22.8 & 16.0 & 2324 \\
SAL19 & $<10$ & $<0.1$ & $<0.1$ & 61.0 & 42.8 & 22.0 & 5540 \\
\hline
\end{tabular}

The parameters that, in some cases, are closer than others to the limits for downgrading to $2^{\text {nd }}$ Class Quality are primarily specific electrical conductivity at $25^{\circ} \mathrm{C}$, TDS and, to a lesser extent, sulphates.

Metal content: For a number of metals, their content was determined for the samples taken, in particular: Al, $\mathrm{Cd}, \mathrm{Co}, \mathrm{Cu}, \mathrm{Ni}, \mathrm{Pb}$ and $\mathrm{Zn}$. The information obtained is shown in Table 5.

Aluminium was present in concentrations that are substantially lower than the MAC $\left(200 \mu \mathrm{g} \mathrm{L}^{-1} \S\right.$ Italian law DPR 236/88).

Cadmium was detected in samples SAL02, SAL09, SAL13, SAL15, SAL16, SAL17 and SAL18 in concentrations that were always below the MAC as per Italian law DLgs. 152/99 (5 $\left.\mu \mathrm{g} \mathrm{L}^{-1}\right)$; only at point SAL16 did the value $\left(3.9 \mu \mathrm{g} \mathrm{L}^{-1}\right)$ approach the legal limit.

Cobalt was found in three wells (SAL4, SAL10 e SAL17) but in only one (SAL17) was there a value of $5.2 \mu \mathrm{g} \mathrm{L}^{-1}$. For this metal no MAC is specified in recent Italian legislation referring to water intended for human consumption (DPR 236/88, DLgs. 152/99 and DLgs. 31/01).

Copper was present in concentrations well below the MAC $\left(1 \mathrm{mg} \mathrm{L}^{-1}\right)$.

Nickel was found in all the samples, with concentrations covering a wide range of values (from 0.7 to $336 \mu \mathrm{g} \mathrm{L}^{-1}$ ). For water intended for human consumption MAC is $20 \mu \mathrm{g} \mathrm{L}^{-1}$ (DLgs. 31/01), therefore, in as many as eight samples (SAL03, SAL04, SAL06, SAL13, SAL14, SAL17, SAL18 and SAL19) the legal limit was exceeded. In some cases (SAL13, SAL14 and SAL18) the values were not far above the 
limit, (by 4, 15 and 14\% respectively), but in others the values were significantly greater $(107,114,279,408$ and $1582 \%$ respectively for SAL17, SAL19, SAL03, SAL04 and SAL06).

For lead, MAC is $10 \mu \mathrm{g} \mathrm{L}^{-1}$ (DLgs. 31/01); in the area under investigation this metal was found in almost all samples, with the exception of points SAL03, SAL06, SAL08 and SAL14. MAC was exceeded at points SAL07, SAL13, SAL16, SAL17, SAL18 and SAL19.

Zinc was present in high concentrations (compared to average results) at points SAL16, SAL17, SAL18 and SAL19. However, only for SAL16 and SAL19 did it exceed MAC (3 $\mathrm{mg} \mathrm{L}^{-1} \S$ DPR 236/88).

\section{CONCLUSION}

The relationships existing between all the factors, which were recorded, analysed and marked on the special subject maps, demonstrate that a large part of the area under examination is characterised by the aquifer's high vulnerability to pollution, while limited sectors have lower vulnerability.

The presence of a range of hazard points and vast maize- and rice- growing areas, but predominantly maize-growing, means that the area under investigation is subject to numerous possible point and diffuse sources of pollution.

By nature of its location of the EUREX plant in Saluggia is in a highly vulnerable context, with environmental conditions that already show significant deterioration.

Analysis of the hydrogeochemic facies highlights differences between the sectors to the right and left of the Dora Baltea, the former with a bicarbonate-calcicmagnesic facies, while the latter has a strongly bicarbonate-calcic facies. This difference delineates a separation between the two parts of the aquifer, which had already been demonstrated by the flow field analysis with the presence of aquifer drainage by the Dora Baltea.

As regards the quality of the groundwater resources for use as drinking water, results clearly show that the whole area under examination is strongly affected by the presence of nitrates in concentrations that exceed the natural threshold $\left(5 \mathrm{mg} \mathrm{L}^{-1}\right)$, evidence of human input with an impact at the limits of environmental sustainability. The state of water quality also shows differences between the two sectors of the aquifer as defined above, with extensive risk due to the presence of iron and manganese in the left bank sector, which were not found in the right bank sector. Overall, therefore, the base quality of the water can be considered seriously harmed for drinking purposes.

The situation is completely different as regards water quality for agricultural use. In this case it was found to be $1^{\text {st }}$ class quality for the whole area under examination, with no differences between the two sectors.

With regard to metal content, there were localised values exceeding the MAC (even substantially at times) for nickel, lead and zinc. The origins of these concentrations were not investigated but is reasonable to suppose that the metals have been carried into the system from outside.

Overall, the situation confirms the existence of non-indifferent impact on groundwater resources caused by human activity, due to both agricultural practice and point pollution phenomena caused by industrial activity and uncontrolled waste disposal. Also in this case the chemical data, especially when georeferenced, are confirmed in the map showing Hazard Points.

The results of the study provide the essential basic information required for future environmental monitoring that may be developed during future decommissioning activities.

\section{REFERENCES}

1. Civita, M. and M.D. Maio, 2000. Valutazione e cartografia automatica della vulnerabilità degli acquiferi all'inquinamento con il sistema parametrico. SINTACS R5 a new parametric system for the assessment and automatic mapping of groundwater vulnerability to contamination. Pitagora Editrice, Bologna pp: 240. Pubbl. n 2200 del GNDCI-CNR.

2. Schoeller, H., 1955. Les Eaux Souterraines. Masson, Paris.

3. Civita, M., A. Fiorucci and G. Olivero, 1998. I diagrammi di qualità per l'utilizzazione delle acque sotterranee destinate al consumo umano e all'agricoltura. GEAM n 4-dicembre 1998. Anno, 35: 259, 266. 